\title{
Hereditary Multiple Exostoses: Clinical, Molecular and Radiologic Survey in 9 Families
}

\author{
Karel Medek ${ }^{1}$, Jiří Zeman ${ }^{1}$, Tomáš Honzík', Hana Hansíková', \\ Štěpánka Švecová', Kamila Beránková', Vendula Kučerová Vidrová1, \\ Miloslav Kuklík ${ }^{2}$, Jiří Chomiak ${ }^{3}$, Markéta Tesařová ${ }^{1}$ \\ ${ }^{1}$ Department of Pediatrics and Adolescent Medicine, First Faculty of Medicine, \\ Charles University and General University Hospital in Prague, Prague, \\ Czech Republic; \\ ${ }^{2}$ Genetic Department, Prague, Czech Republic; \\ ${ }^{3}$ Department of Orthopaedics, First Faculty of Medicine, Charles University \\ and $\mathrm{Na}$ Bulovce Hospital, Prague, Czech Republic
}

Received March 22, 2017; Accepted August 28, 2017.

Key words: Multiple exostoses - EXT1 - EXT2

\begin{abstract}
Hereditary multiple exostoses (HME) represents a heterogeneous group of diseases often associated with progressive skeletal deformities. Most frequently, mutations in EXT1 and EXT2 genes with autosomal dominant inheritance are responsible for HME. In our group of 9 families with HME we evaluated the clinical course of the disease and analysed molecular background using Sanger sequencing and MLPA in EXT1 and EXT2 genes. The mean age in our group of patients, when the first exostosis was recognised was 4.5 years (range 2-10 years) and the number of exostoses per one patient documented on X-ray ranged from 2 to 54. Most of the exostoses developed before the growth was completed and they were dominantly localised in the distal femurs, proximal tibia, proximal humerus and distal radius. In all patients, at least one to 8 surgeries were necessary due to complaints and local complications, but neither patient
\end{abstract}

This study was supported by grant AZV 16-31932A from the Ministry of Health of the Czech Republic and by institutional research support PROGRES Q32/LF2 from the Charles University and RVO-VFN64165/2012 from the Ministry of Health of the Czech Republic.

Mailing Address: Ing. Markéta Tesařová, PhD., Department of Pediatrics and Adolescent Medicine, First Faculty of Medicine, Charles University and General University Hospital in Prague, Ke Karlovu 2, 12808 Prague 2, Czech Republic; Phone: +420 224967 748; e-mail: marketa.tesarova@If1.cuni.cz 
developed malignant transformation. In half of the patients, the disease resulted in short stature. DNA analyses were positive in 7 families. In five probands, different EXT1 gene mutations resulting in premature stop-codon (p.Gly124Argfs*65, p.Leu191*, p.Trp364Lysfs*11, p.Val371Glyfs*10, p.Leu490Profs*31) were found. In two probands, nonsense mutations were found in EXT2 gene (p.Val187Profs*115, p.Cys319fs*46). Five mutations have been novel and two mutations have occurred de novo in probands. Although the risk for malignant transformation is usually low, especially in patients with low number of exostoses, early diagnostics and longitudinal follow up of patients is of a big importance, because early surgery can prevent progression of secondary bone deformities.

\section{Introduction}

Hereditary multiple exostoses (HME) manifests as remodelling deformities in bones due to disturbed chondrocyte proliferation and maturation that leads to abnormal bone growth and development of isolated or multiple exophytic masses near the joints of long bones (Karasick et al., 1997; Stieber and Dormans, 2005; Kok et al., 2013). HME belongs to the group of glycosaminoglycan biosynthesis deficiencies associated with skeletal and connective tissue disorders (Hennet and Cabalzar, 2015). The inheritance of HME is autosomal dominant and most patients have non-sense mutation in the EXT1 gene on chromosome 8q24 or EXT2 gene on chromosome 11p11-13 encoding exostosin glycosyltransferase 1 and 2 (EXT1; OMIM *608177 and EXT2; OMIM *608210) (Wuyts et al., 1998; Francannet et al., 2001).

Exostoses are localised most frequently in the metaphyses of long bones, but they may also develop on the diaphyses of long bones. They are usually painless, but secondary complaints may arise due local pressure of exostosis on neighbouring areas of soft tissues. Bone lesions on flat bones, vertebrae, and the ribs are less common and the skull is usually not involved (OMIM \#133700).

We present the results of clinical, radiologic and molecular survey in 9 families with hereditary multiple exostoses.

\section{Methods}

Total genomic DNA was available from all patients and parents of patient 4 and patient 9. All exons of EXT1 (ENSG00000182197; ENST00000378204) and EXT2 (ENSG00000151348; ENST00000395673) genes were amplified by PCR from genomic DNA isolated from leukocytes and analyzed by direct sequencing using $3500 x \mathrm{~L}$ genetic analyzer (Applied Biosystems, USA). PCR primers are available upon request. All samples were tested for large deletions/duplications using the SALSA MLPA P215-B2 EXT probe mix (MRC-Holland, Amsterdam, Netherlands) according to the manufacturer's instructions. Fragment analysis was performed on 3500xL genetic analyzer (Applied Biosystems, USA), and the MLPA data were analysed using Coffalyser.Net software (MRC-Holland, Netherlands). 


\section{Ethics}

The study was approved by the Ethics Committee of the General University Hospital in Prague and was conducted in agreement with institutional guidelines. Written informed consent for molecular analyses was obtained from all patients and parents of affected children.

\section{Results}

\section{Patients}

Altogether, 9 probands and 3 other family members with multiple exostoses at the age between 6 and 76 years and two 18 months old girls from family 4 were recommended to our outpatient clinic for skeletal dysplasia for genetic testing and counselling. All but one proband are Caucasians from different regions of the Czech Republic, one proband is offspring of parents from the Czech Republic and Asia.

The average age, when the first exostosis was recognized clinically, was 4.5 years (range 2-10 years) and the average age, when the diagnosis of multiple exostoses was confirmed by radiographic examinations, was 8.6 years (range 3-15 years) (Table 1). Exostoses in our patients were dominantly localised in distal femur, proximal tibia, proximal humerus and distal radius (Figure 1). Most of the exostoses developed during pubertal growth spurt. Stabilisation of the disease occurred after

Table 1 - Clinical data and results of radiographic examination in 9 families with hereditary multiple exostoses

\begin{tabular}{lccccccc}
\hline Family & Patient & $\begin{array}{c}\text { Relationship } \\
\text { to the } \\
\text { proband }\end{array}$ & $\begin{array}{c}\text { Age } \\
\text { (years) }\end{array}$ & $\begin{array}{c}\text { Growth } \\
\text { (percen- } \\
\text { tile) }\end{array}$ & $\begin{array}{c}\text { Age at } \\
\text { onset/age } \\
\text { at diagnosis }\end{array}$ & $\begin{array}{c}\text { Number of } \\
\text { exostoses } \\
\text { on X-rays }\end{array}$ & $\begin{array}{c}\text { Number } \\
\text { of } \\
\text { surgeries }\end{array}$ \\
\hline 1 & 1 & proband & 16 & $<1$ & $3 / 3$ years & 31 & 2 \\
& 2 & mother & 48 & 30 & $4.5 / 14$ years & 19 & 1 \\
\hline 2 & 3 & grandmother & 76 & $<1$ & $6 / 15$ years & 30 & $?$ \\
\hline 3 & 4 & proband & 11 & 40 & $2 / 3$ years & 54 & 3 \\
\hline 4 & 5 & proband & 19 & 2.6 & $0-3 / 3$ years & 36 & 7 \\
\hline 5 & 7 & proband & 30 & 50 & $6 / 9$ years & 35 & 7 \\
\hline 6 & 8 & daughter A & 1.5 & 20 & - & 0 & - \\
\hline 7 & 10 & probaghter B & 1.5 & 20 & - & 0 & - \\
\hline 8 & 11 & proband & 32 & 30 & $3 / 13$ years & 28 & 8 \\
\hline 9 & 12 & proband & 9 & 13 & $4 / 4$ years & 16 & 2 \\
\hline & 13 & proband & 10 & 0.7 & $9 / 10$ years & 39 & - \\
\hline
\end{tabular}



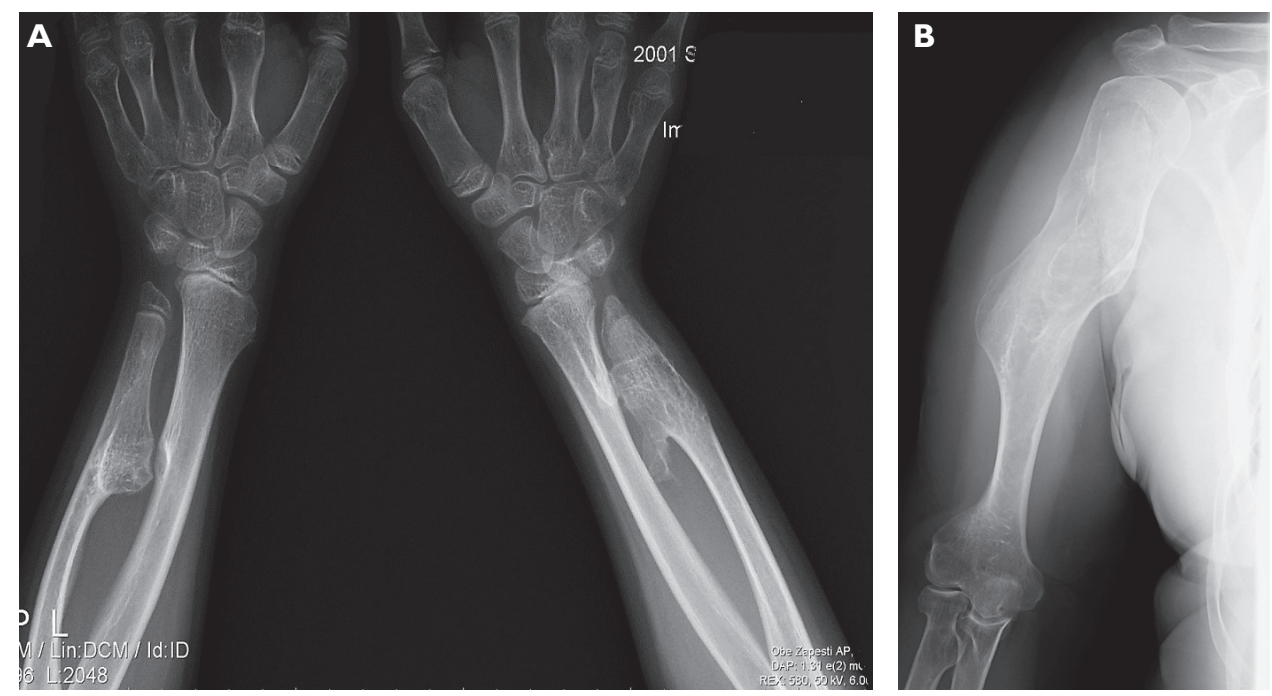

Figure 1 - Different size and localisation of exostoses in five patients with multiple hereditary exostoses due to heterozygous nonsense mutations in EXT1 and EXT2 genes.

A) Exostoses on distal forearms cause deformation of diametaphyses of long bones. Significant exostoses are located particularly on ulnae leading to their relative shortening, outward bowing of radii and formation of "bayonet hand" deformity of the forearm (P1 at the age of 13 years); B) Significant broad exostoses are apparent on the proximal metaphysis and on the upper half of proximal diaphysis of the right humerus with a significant deformity of the humeral diametaphysis ( $P 3$ at the age of 71 years).

the growth was completed, but the disease resulted in the short stature in 6 out of 13 patients (46\%). The number of exostoses per one patient documented on X-ray ranged from 2 to 54 (Table 1). In practically all patients, at least one to 8 surgeries were necessary due to complaints and local complications of exostoses, but no patient developed malignant transformation, so far.

\section{Mutation analysis of EXT1 and EXT2 genes}

DNA analyses in 7 patients from 5 families revealed the presence of heterozygous mutation in EXT1 gene and mutation in EXT1 was also found in two asymptomatic young girls (P7, P8) from family 4. Mutations in EXT2 gene were found in three patients P12, P13 and P14 (mother of P13). Five mutations have been novel and two mutations, one in each analysed gene, have occurred de novo in probands (Table 2). Large deletions/duplications affecting EXT1 and EXT2 genes were not found.

\section{Discussion}

Both enzymes, exostosin glycosyltransferase 1 and exostosin glycosyltransferase 2 (EXT1 and EXT2), are involved in the synthesis of heparan sulphate proteoglycans 

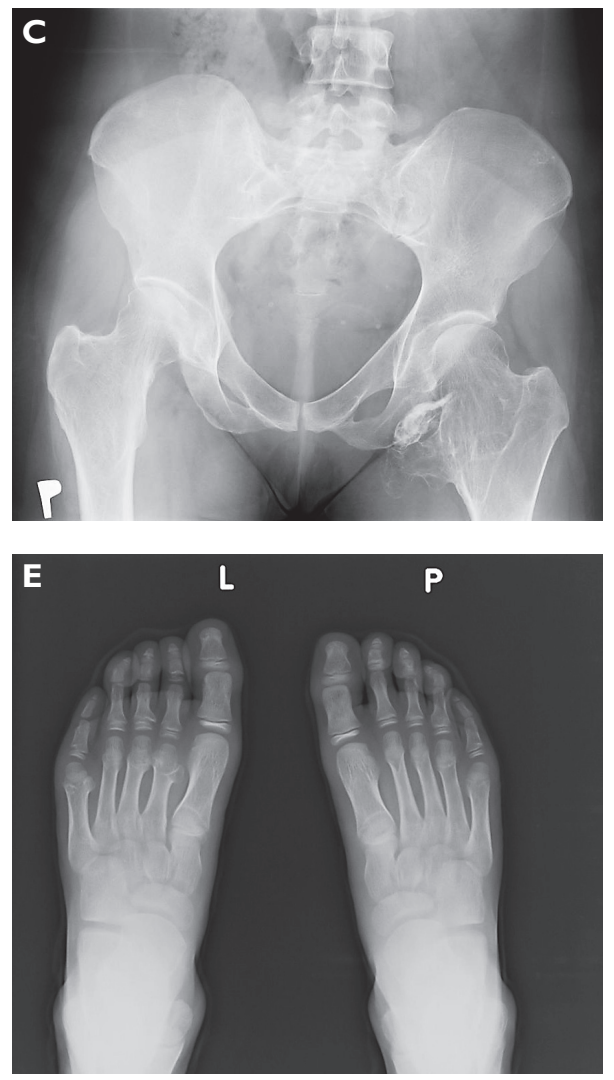

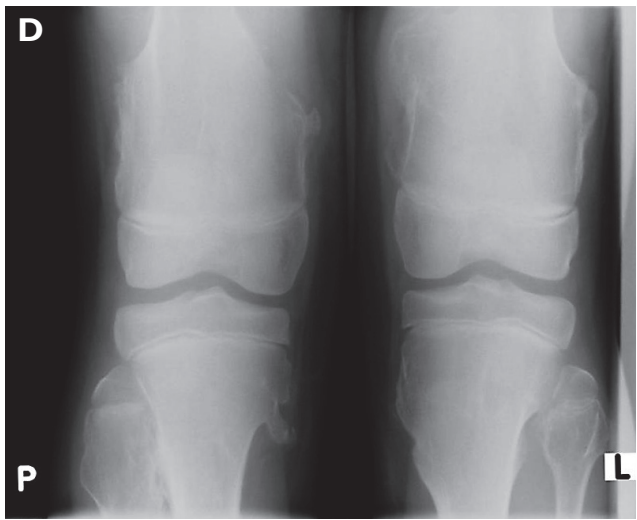

Figure 1 - C) Two exostoses localized on left proximal femur causing deformity of left hip joint. The larger exostosis is broad-based with lower bone density, the smaller one is pedunculated with higher bone density (P2 at the age of 41 years); D) Multiple exostoses localized on distal parts of diaphyses and metaphyses of femora and proximal parts of tibiae and fibulae, some of them are hook-like and protrudes into the soft tissues (P4 at the age of 9.5 years); E) Multiple exostoses on most of metatarsal bones bilaterally, very significant particularly on metatarsal bone II and V on the left, other exostoses are on proximal phalanges of finger II-V on the left and proximal phalange of the finger IV on the right ( $\mathrm{P} 13$ at the age of 9.5 years).

on the cell surface and in the extracellular matrix (Wuyts et al., 1998; Francannet et al., 2001). EXT1 and EXT2 genes encoding these enzymes have tumour suppressor function and mutations in EXT1 and EXT2 genes may cause a loss of heterozygosity (LOH). It means a 2-hit tumour formation model, when a single germ-line mutation in EXT1 or EXT2 results in the predisposition for disease and the second local somatic mutation allows for aberrant growth of exostoses (Hecht et al., 1995; Raskind et al., 1995).

Growth of exostoses may result in short stature, limb-length discrepancies, valgus deformities of the knee and ankle, asymmetry of the pectoral and pelvic girdles, bowing of the radius with ulnar deviation of the wrist, and subluxation of the radiocapitellar joint (Stieber and Dormans, 2005). In both aspects, clinical and radiological, the group of our patients corresponds well with other studies describing the localisation of exostosis predominantly around the knee (Bovée, 2008).

The prevalence of HME is estimated at 1:50 000, and it seems to be higher in males (male-to-female ratio 1.5:1) (Bovée, 2008). In our study, only half of probands 


\section{Table 2 - EXT1 and EXT2 mutations found in 9 families with hereditary} multiple exostoses

\begin{tabular}{|c|c|c|c|c|c|}
\hline Patient & Gene & Mutation & $\begin{array}{l}\text { Predicted } \\
\text { protein change }\end{array}$ & $\begin{array}{l}\text { de novo } \\
\text { mutation }\end{array}$ & Reference \\
\hline 1 & EXT1 & c. $572 T>G$ & p.Leu191* & & novel \\
\hline 2 & EXT1 & c. $572 \mathrm{~T}>\mathrm{G}$ & p.Leu191* & & novel \\
\hline 3 & EXT1 & c. $572 \mathrm{~T}>\mathrm{G}$ & p.Leu191* & & novel \\
\hline 4 & EXT1 & c.1112delT & p.Val371Glyfs*10 & yes & novel \\
\hline 5 & EXT1, EXT2 & negative & & & \\
\hline 6 & EXT1 & c.369dupA & p.Gly124Argfs*65 & & novel \\
\hline 7 & EXT1 & c.369dupA & p.Gly124Argfs*65 & & novel \\
\hline 8 & EXT1 & c.369dupA & p.Gly124Argfs*65 & & novel \\
\hline 9 & EXT1 & c.1468dupC & p.Leu490Profs*31 & yes & $\begin{array}{l}\text { Seki et al. } \\
\text { (2001) }\end{array}$ \\
\hline 10 & EXT1 & $\begin{array}{l}\text { c.1092_1100delinsCTC } \\
\text { AGAAATTGCTCAGCA }\end{array}$ & p.Trp364Cysfs*11 & $\begin{array}{l}\text { not } \\
\text { tested }\end{array}$ & novel \\
\hline 11 & EXT1, EXT2 & negative & & & \\
\hline 12 & EXT2 & c.956delG & p.Cys $319 \mathrm{fs} * 46$ & $\begin{array}{l}\text { not } \\
\text { tested }\end{array}$ & novel \\
\hline 13 & EXT2 & c.459_462delTGTT & p.Val187Profs*115 & & $\begin{array}{l}\text { Song et al. } \\
\text { (1999) }\end{array}$ \\
\hline 14 & EXT2 & c.459_462delTGTT & p.Val187Profs*115 & & $\begin{array}{l}\text { Song et al. } \\
\text { (1999) }\end{array}$ \\
\hline
\end{tabular}

are males. The diagnosis of HME in childhood is mostly based on family history of the disease with autosomal dominant inheritance, clinical evaluation, radiographic examination and genetic testing.

The results of molecular analyses in our study are in agreement with the literature. Most mutations in EXT1 and EXT2 in families with HME are private. A more severe course of the disease was shown to be significantly associated with mutations in EXT1 gene, whereas a moderate phenotype is more often associated with mutations in EXT2 (Francannet et al., 2001; Heinritz et al., 2009). In our study, mutations in EXT1 gene were found in 55\% of probands. It is a much less than $85 \%$ found in 33 unrelated Polish patients (Jamsheer et al., 2014). Mutations in EXT2 gene were found in two probands. All except two mutations identified in our study are novel. EXT1 mutation p.Leu490Profs*31 in proband 5 and ETX2 mutation p.Val187Profs*115 found in family 9 have been already described (Song et al., 1999; Seki et al., 2001). In our families with HME, the molecular basis of the disease was not recognized in $22 \%$ of probands. In recent study of significantly larger patient 
group (112 patients) from Japan, $34 \%$ of patients did not exhibit mutations in EXT1 or EXT2 genes (Ishimaru et al., 2016).

Precise diagnostics in patients with multiple exostoses is not always easy, especially in patients without mutation in EXT1 and EXT2 genes, because exostosis may also develop in other clinical conditions including metachondromatosis (OMIM \#156250) and the Langer-Giedion syndrome (LGS; OMIM \#150230) also known as trichorhinophalangeal syndrome type II and in patients with fibrodysplasia ossificans progressiva (FOP; OMIM \#135100), occipital horn syndrome (OMIM \#304150), and the adult stage of hereditary hypophosphatemia (OMIM \#307800); these exostoses are located at sites of tendon and muscle attachment. A relatively rare variant of the supracondylar process, on the anteromedial surface of the distal humerus, can be confused with an exostosis; the variant is said to be present in about $1 \%$ of persons of European descent (Silverman, 1985). Recently, exostosinlike glycosyltransferase 3 (EXTL3) that regulates the biosynthesis of heparan sulphate $(\mathrm{HS})$ and is important for both skeletal development and haematopoiesis has been linked to distinct clinical phenotype by two groups. EXTL3 mutations are responsible for "neuro-immuno-skeletal dysplasia syndrome" with variable skeletal abnormalities, neurodevelopmental defects and combined immunodeficiency (Oud et al., 2017; Volpi et al., 2017).

\section{Conclusion}

Early diagnostics and longitudinal follow up of patients with hereditary multiple exostoses are of great importance. In some patients, surgery can prevent progression of secondary deformities. Although the risk for malignant transformation of the cartilaginous portion of the exostosis in patients with isolated exostosis is usually low $(0.5-1 \%)$, the risk increases in patients with multiple exostoses up to 5\% (Vanhoenacker et al., 2001; Stieber and Dormans, 2005; Bovée, 2008). The onset of malignant transformation towards secondary peripheral chondrosarcoma is most frequent in the fourth decade, it seldom occurs in children below 10 years and adults after 50 years (Ochsner, 1978).

\section{References}

Bovée, J.V. (2008) Multiple osteochondromas. Orphanet J. Rare Dis. 13, 3.

Francannet, C., Cohen-Tanugi, A., Le Merrer, M., Munnich, A., Bonaventure, J., Legeai-Mallet, L. (2001) Genotype-phenotype correlation in hereditary multiple exostoses. J. Med. Genet. 38, 430-434.

Hecht, J. T., Hogue, D., Strong, L. C., Hansen, M. F., Blanton, S. H., Wagner, M. (1995) Hereditary multiple exostoses and chondrosarcoma: Linkage to chromosome II and loss of heterozygosity for EXT-linked markers on chromosomes 2 and 8. Am. J. Hum. Genet. 56, 1125-1131.

Heinritz, W., Hüffmeier, U., Strenge, S., Miterski, B., Zweier, C., Leinung, S., Bohring, A., Mitulla, B., Peters, U., Froster, U. G. (2009) New mutations of EXT1 and EXT2 genes in German patients with multiple osteochondromas. Ann. Hum. Genet. 73, 283-291.

Hennet, T., Cabalzar, J. (2015) Congenital disorders of glycosylation: a concise chart of glycocalyx dysfunction. Trends Biochem. Sci. 40, 377-384. 
Ishimaru, D., Gotoh, M., Takayama, S., Kosaki, R., Matsumoto, Y., Narimatsu, H., Sato, T., Kimata, K., Akiyama, H., Shimizu, K., Matsumoto, K. (2016) Large-scale mutational analysis in the EXT1 and EXT2 genes for Japanese patients with multiple osteochondromas. BMC Genet. 17, 52.

Jamsheer, A., Socha, M., Sowińska-Seidler, A., Telega, K., Trzeciak, T., Latos-Bieleńska, A. (2014) Mutational screening of EXT1 and EXT2 genes in Polish patients with hereditary multiple exostoses. J. Appl. Genet. 55, 183-188.

Karasick, D., Schweitzer, M. E., Eschelman, D. J. (1997) Symptomatic osteochondromas: imaging features. AJR Am. J. Roentgenol. 168, 1507-1512.

Kok, H. K., Fitzgerald, L., Cambell, N., Lyburn, I. D., Munk, P. L., Buckley, O., Torreggiani, W. C. (2013) Multimodality imaging features of hereditary multiple exostoses. Br. J. Radiol. 86, 20130398.

Ochsner, P. E. (1978) Multiple cartilaginous exostoses and neoplastic degeneration: review of the literature (author's transl.). Z. Orthop. Ihre Grenzgeb. 116, 369-378. (in German)

OMIM - Online Mendelian Inheritance in Man (2017) An Online Catalog of Human Genes and Genetic Disorders. McKusick-Nathans Institute of Genetic Medicine, Johns Hopkins University, Baltimore. Available at: https://omim.org/

Oud, M. M., Tuijnenburg, P., Hempel, M., van Vlies, N., Ren, Z., Ferdinandusse, S., Jansen, M. H., Santer, R., Johannsen, J., Bacchelli, C., Alders, M., Li, R., Davies, R., Dupuis, L., Cale, C. M., Wanders, R. J., Pals, S. T., Ocaka, L., James, C., Müller, I., Lehmberg, K., Strom, T., Engels, H., Williams, H. J., Beales, P., Roepman, R., Dias, P., Brunner, H. G., Cobben, J. M., Hall, C., Hartley, T., Le Quesne Stabej, P., Mendoza-Londono, R., Davies, E. G., de Sousa, S. B., Lessel, D., Arts, H. H., Kuijpers, T.W. (2017) Mutations in EXTL3 cause neuro-immuno-skeletal dysplasia syndrome. Am. J. Hum. Genet. 100, 281-296.

Raskind, W. H., Conrad, E. U., Chansky, H., Matsushita, M. (1995) Loss of heterozygosity in chondrosarcomas for markers linked to hereditary multiple exostoses loci on chromosomes 8 and 11. Am. J. Hum. Genet.

56, 1132-1139.

Seki, H., Kubota, T., Ikegawa, S., Haga, N., Fujioka, F., Ohzeki, S., Wakui, K., Yoshikawa, H., Takaoka, K., Fukushima, Y. (2001) Mutation frequencies of EXT1 and EXT2 in 43 Japanese families with hereditary multiple exostoses. Am. J. Med. Genet. 99, 59-62.

Silverman, F. N. (1985) Caffey's Pediatric X-ray Diagnosis:An Integrated Imaging Approach, Vol. 1. Year Book Medical Publishers, Chicago.

Song, G., Zhou, J., Xia, J., Deng, H., Xu, L., Ruan, Q. (1999) Identification of mutations in the human EXT1 and EXT2 genes. Zhonghua Yi Xue Yi Chuan Xue Za Zhi 16, 208-210. (in Chinese)

Stieber, J. R., Dormans, J. P. (2005) Manifestations of hereditary multiple exostoses. J. Am. Acad. Orthop. Surg. 13, 110-120.

Vanhoenacker, F. M., Van Hul, W., Wuyts, W., Willems, P. J., De Schepper, A. M. (2001) Hereditary multiple exostoses: from genetics to clinical syndrome and complications. Eur. J. Radiol. 40, 208-217.

Volpi, S., Yamazaki, Y., Brauer, P. M., van Rooijen, E., Hayashida, A., Slavotinek, A., Sun Kuehn, H., Di Rocco, M., Rivolta, C., Bortolomai, I., Du, L., Felgentreff, K., Ott de Bruin, L., Hayashida, K., Freedman, G., Marcovecchio, G. E., Capuder, K., Rath, P., Luche, N., Hagedorn, E. J., Buoncompagni, A., Royer-Bertrand, B., Giliani, S., Poliani, P. L., Imberti, L., Dobbs, K., Poulain, F. E., Martini, A., Manis, J., Linhardt, R. J., Bosticardo, M., Rosenzweig, S. D., Lee, H., Puck, J. M., Zúñiga-Pflücker, J. C., Zon, L., Park, P.W., SupertiFurga, A., Notarangelo, L. D. (2017) EXTL3 mutations cause skeletal dysplasia, immune deficiency, and developmental delay. J. Exp. Med. 214, 623-637.

Wuyts, W., Van Hul,W., De Boulle, K., Hendrickx, J., Bakker, E., Vanhoenacker, F., Mollica, F., Ludecke, H. J., Sayli, B. S., Pazzaglia, U. E., Mortier, G., Hamel, B., Conrad, E. U., Matsushita, M., Raskind, W. H., Willems, P. J. (1998) Mutations in the EXT1 and EXT2 genes in hereditary multiple exostoses. Am. J. Hum. Genet. 62, 346-354.

Medek K. et al. 